\title{
Three-dimensional Investigation of Ceramic/Metal Heterophase Interfaces by Atom-probe Microscopy
}

\author{
Jörg Rüsing, Jason T. Sebastian, Olof C. Hellman, and David N. Seidman* \\ Department of Materials Science and Engineering, Northwestern University, 2225 N. Campus Drive, Evanston, IL 60208-3108
}

\begin{abstract}
The results of a three-dimensional atom probe (3DAP) analysis, on a subnanometer scale, of a ceramic/metal heterophase interface, $\mathrm{MgO} / \mathrm{Cu}$, are presented. Segregation of $\mathrm{Ag}$, from the $\mathrm{Cu}(\mathrm{Ag}) \mathrm{matrix}$, at $\mathrm{MgO} / \mathrm{Cu}$ interfaces is investigated and the Gibbsian interfacial excess of silver is determined; the range is 2.33 $\times 10^{18}$ to $5.81 \times 10^{18} \mathrm{~m}^{-2}$. Also, silver segregation at the same $\mathrm{MgO} / \mathrm{Cu}$ interfaces is analyzed employing a new approach that utilizes a proximity histogram or proxigram.
\end{abstract}

Key words: heterophase interfaces, $\mathrm{MgO} / \mathrm{Cu}$, three-dimensional atom-probe microscopy, interfacial segregation, silver, proxigram, ceramic/metal interfaces

\section{INTRODUCTION}

Ceramic/metal (C/M) interfaces are ubiquitous throughout both science and industry. They play an important role in a variety of important technological applications including metal-matrix composites, supported catalysts, electronic packaging, and thermal barrier coatings on nickel- or ironbased superalloys employed at elevated temperatures.

The scientific study of $\mathrm{C} / \mathrm{M}$ heterophase interfaces is in a nascent stage, particularly with respect to the atomic-scale study of segregation of specific alloying elements at these interfaces (Rühle et al., 1990; Mader and Rühle, 1992; Ernst, 1995; De Hosson et al., 1996). It is well known, for example, that impurity segregation at $\mathrm{C} / \mathrm{M}$ interfaces has a deleterious effect in various technological applications (Felten and Pettit, 1976); for example, void formation at $\alpha-\mathrm{Al}_{2} \mathrm{O}_{3} / \mathrm{Ni}$ interfaces due to sulfur segregation leads to exfoliation of

Received November 15, 1999; accepted March 28, 2000.

*Corresponding author the protective thermal barrier coating. The study of impurity segregation at $\mathrm{C} / \mathrm{M}$ interfaces, however, has been limited and a fundamental understanding of segregation behavior at $\mathrm{C} / \mathrm{M}$ heterophase interfaces is lacking.

A significant fraction of the research concerning atomic-scale characterization of $\mathrm{C} / \mathrm{M}$ interfaces has been performed on model systems (Ernst, 1995). Such systems are prepared by a variety of methods including internal oxidation, diffusion bonding, and molecular beam epitaxy (Ernst, 1995). The atomic-resolution techniques employed to study model interfaces have included one-dimensional atom-probe field-ion microscopy (1D-APFIM), highresolution transmission electron microscopy (HREM), Zcontrast microscopy in a dedicated scanning transmission electron microscope (STEM), and electron energy-loss spectroscopy (EELS) in a dedicated STEM. In this article, we present the first results applying three-dimensional atom-probe field-ion microscopy (3DAP) (Blavette et al., 1993; Cerezo et al., 1998; Deconihout et al., 1999) to the study of segregation of silver at $\mathrm{MgO} / \mathrm{Cu}$ interfaces, prepared by internal oxidation. 
Recently, the system $\{222\} \mathrm{MgO} / \mathrm{Cu}$ has been studied extensively (Shashkov et al., 1999a,b). The attractiveness of this particular system is attributable directly to the atomically clean and atomically sharp interfaces that can be produced by internal oxidation of high purity $\mathrm{Cu}(\mathrm{Mg}, \mathrm{Ag}$ ) alloys. The utilization of a Rhines pack to oxidize internally a $\mathrm{Cu}(\mathrm{Mg}, \mathrm{Ag})$ alloy produces octahedral-shaped $\mathrm{MgO}$ precipitates faceted on the close-packed $\{222\}$ polar planes within a Cu matrix (Jang et al., 1993). Both experimental (Jang et al., 1993; Muller et al., 1998) and theoretical (Benedek et al., 1996) results have shown that these precipitates are preferentially O-terminated. An EELS investigation of the $\{222\} \mathrm{MgO} / \mathrm{Cu}$ interface has provided evidence for metal-induced gap states (MIGS) at this interface (Muller et al., 1998), which represents the first experimental observation of MIGS at any heterophase interface. In addition, one-dimensional APFIM and EELS investigations of this interface have permitted observation of Ag segregation on an atomic scale (Shashkov and Seidman, 1995, 1996; Shashkov et al., 1999b). Silver segregation was measured quantitatively and the Gibbsian interfacial excess was directly determined (Shashkov and Seidman, 1995, 1996; Shashkov et al., 1999b). Furthermore, the $\{222\} \mathrm{MgO} / \mathrm{Cu}$ interface has been studied extensively employing local density functional theory (LDFT) and molecular dynamics (MD) simulation (Benedek et al., 1996, 1997, 1999, 2000).

\section{Materials and Methods}

An alloy with the nominal composition Cu-2.5 at.\% Mg-0.8 at.\% Ag was prepared by vacuum arc melting (the purity levels of the constituent elements were 99.999 wt.\% Cu, 99.99 wt.\% Mg, and 99.999 wt.\% Ag). The arc-melted ingot was swaged into a small rod and subsequently drawn into $200 \mu \mathrm{m}$ diameter wires. The wires were then internally oxidized employing a Rhines pack, which consists of a mixture of $\mathrm{Cu}, \mathrm{Cu}_{2} \mathrm{O}$, and $\mathrm{Al}_{2} \mathrm{O}_{3}$ powders (1:1:1 by volume); the $\mathrm{Al}_{2} \mathrm{O}_{3}$ is employed to prevent sintering of the Rhines pack. Internal oxidation was performed at a temperature of $950^{\circ} \mathrm{C}$ for $2 \mathrm{hr}$. At this temperature, the Rhines pack establishes an equilibrium oxygen partial pressure of $10^{-2} \mathrm{~Pa}$, ultimately leading to the formation of octahedral-shaped $\mathrm{MgO}$ precipitates within the $\mathrm{Cu}$ matrix at a number density of $1 \times$ $10^{23} \mathrm{~m}^{-3}$ and a mean diameter of $20 \mathrm{~nm}$ (Shashkov et al., 1999a). To maximize the segregation of $\mathrm{Ag}$ at the $\mathrm{MgO} / \mathrm{Cu}$ interface, a segregation anneal was performed under an atmosphere of pure argon at $500^{\circ} \mathrm{C}$ for $72.5 \mathrm{hr}$; the minimum root-mean squared diffusion distance of $\mathrm{Ag}$ in $\mathrm{Cu}$ is approximately $\sqrt{2 D t}=1520 \mathrm{~nm}$ in one dimension (Barreau et al., 1970). Thus, at the very least, the silver at the $\mathrm{MgO} / \mathrm{Cu}$ interfaces is in local equilibrium with the silver in the copper matrix.

Three-dimensional atom-probe results were obtained using the energy compensated optical position-sensitive atom probe (ECOPoSAP) in the laboratory of Professor G.D.W. Smith at the University of Oxford, Oxford, UK (Cerezo et al., 1998); this research was performed as part of a contractual agreement between Northwestern University and Kindbrisk Limited. Data collection was performed at a specimen temperature of $50 \mathrm{~K}$ with a voltage pulse fraction (f) of 0.15 ( $\mathrm{f}$ is the ratio of the pulse voltage to the steadystate dc voltage), a pulse frequency of $1500 \mathrm{~Hz}$, and a background pressure of $2 \times 10^{-8} \mathrm{~Pa}$. A total of 391,877 ions were collected in an analysis volume close to the 111 pole of the specimen. The areal dimensions are scaled using two important calibration factors: (1) the tip radius of a copper specimen at $10 \mathrm{kV}, 60 \mathrm{~nm}$; and (2) the image compression factor, $\kappa=1.9$ (Rozdilsky, 1999). A length calibration for the depth scale is performed by identifying the $\{111\}$ planes in the reconstructed volume and scaling the data set until the measured interplanar spacing is equal to the known interplanar spacing of copper; the value used for the reconstruction in Figure 1 was 3706 ions $\mathrm{nm}^{-1}$ at $10 \mathrm{kV}$ for a flight path of $0.613 \mathrm{~m}$. Atomic planes could not be imaged in the vicinity of the precipitates.

\section{Results And Discussion}

The results of the three-dimensional atom-probe analysis are presented in Figure 1, which displays a 3D reconstruction of a $\mathrm{MgO}$ precipitate in a copper matrix. The magnesium atoms are in red, the oxygen atoms are in green, and the silver atoms are in blue. To distinquish clearly the $\mathrm{MgO}$ precipitate from the copper matrix, the copper matrix atoms are colored green and are smaller than the other elements. The overall dimensions of the reconstructed volume (rectangular parallelepiped) in Figure 1 are $17 \mathrm{~nm} \times 17 \mathrm{~nm}$ $\times 57.1 \mathrm{~nm}\left(16,502 \mathrm{~nm}^{3}\right)$. To investigate both the chemistry of the $\mathrm{MgO}$ precipitates and the $\mathrm{MgO} / \mathrm{Cu}$ interfacial chemistry, an analysis cylinder with a specified diameter is superimposed onto the overall data set (see Fig. 1). In the literature of $3 \mathrm{D}$ atom-probe investigations, analysis of the chemistry of precipitates and interfaces is commonly performed by defining a rectangular parallelepiped as the re- 


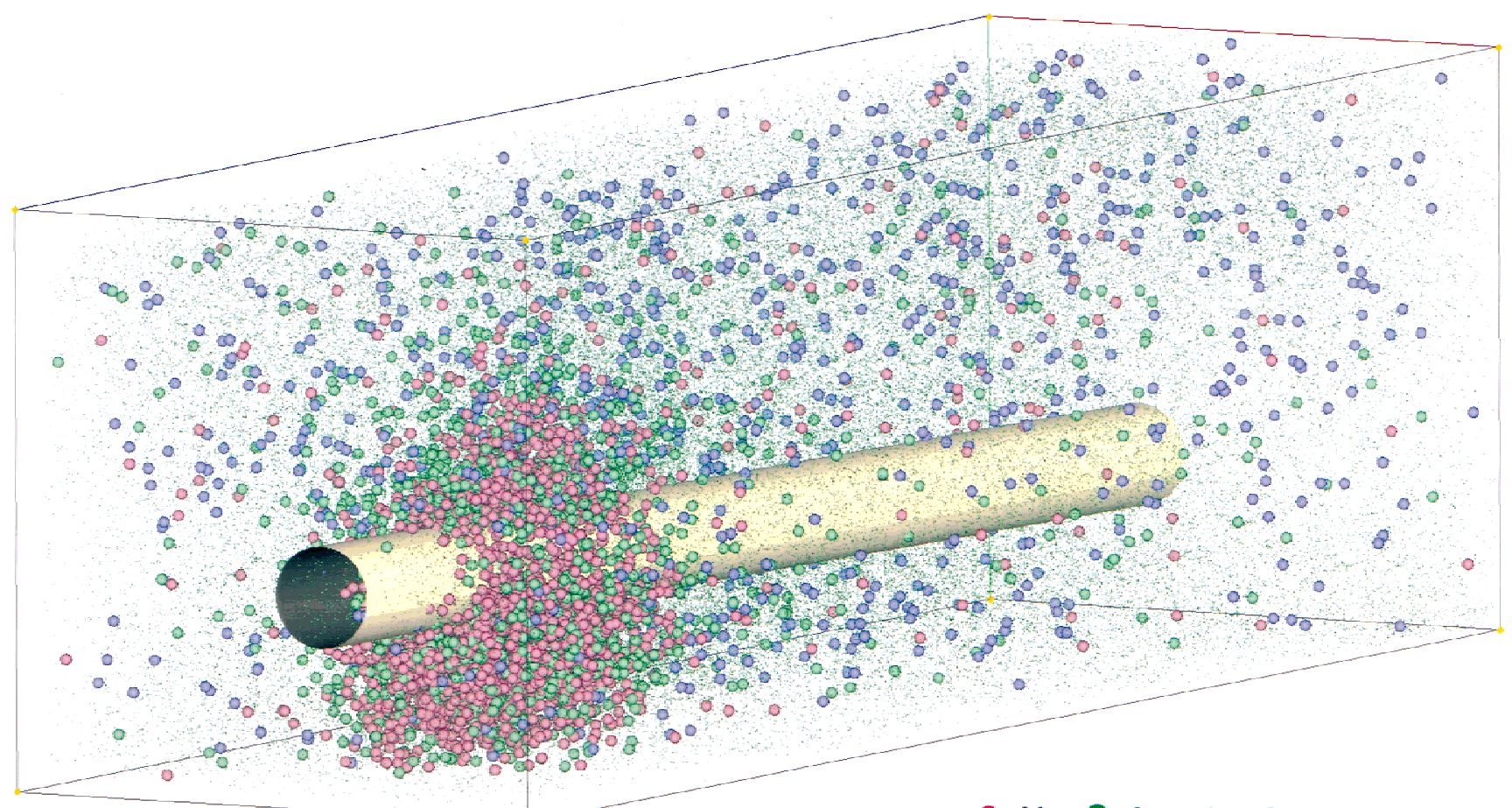

Figure 1. Three-dimensional atom-probe atomic reconstruction of an internally oxidized $\mathrm{Cu}(\mathrm{Mg}, \mathrm{Ag}$ ) alloy (analysis direction is along $\approx\langle 111\rangle$ ). The dimensions of the rectanglar parallelepiped are

gion of interest, and one of the edges of the parallelepiped is taken to be the direction of analysis. In contrast, we define a right circular cylinder around an axis in the direction of the analysis, because the distance from the cylinder axis to the edges of the cylinder is constant. The long axis of this cylinder is aligned such that it is approximately normal to the $\{111\}$ matrix planes in the data reconstruction. The diameter, $\mathrm{d}$, of the analysis cylinder is varied from 1 to $4 \mathrm{~nm}$.

Figure 2 shows four integral profiles for the analysis cylinder shown in Figure 1; each one has a different analysis cylinder diameter $(\mathrm{d}=1,2,3$, or $4 \mathrm{~nm})$. Note that each integral profile is divided into five sections, denoted by the Roman numerals I to V. Section I represents the copper matrix. Noting that the analysis cylinder is approximately normal to the $\{111\}$ planes of the matrix, section II contains the anterior interface region between the copper matrix and the $\mathrm{MgO}$ precipitate as analyzed in the $\approx\langle 111\rangle$ direction. Section III contains the $\mathrm{MgO}$ precipitate, while section IV contains the posterior interface between the $\mathrm{MgO}$ precipitate and the copper matrix. Due to the position of the analysis cylinder with respect to the $\mathrm{MgO}$ precipitate, this interface is not exactly at $90^{\circ}$ to the $\langle 111\rangle$ direction. As a
$17 \mathrm{~nm} \times 17 \mathrm{~nm} \times 57.1 \mathrm{~nm}$. One of the $\mathrm{MgO}$ precipitates in the copper matrix is exhibited: $\mathrm{Mg}$ atoms (red); $\mathrm{O}$ atoms (green); $\mathrm{Ag}$ atoms (blue); and $\mathrm{Cu}$ atoms (small green dots).

result, section IV represents more than $5 \mathrm{~nm}$ of depth in the analysis direction; see the upper vertical scale on the integral profiles of Figure 2. After the anterior interface of the $\mathrm{MgO}$ precipitate, the copper matrix is contained in section $\mathrm{V}$ of the integral profiles.

Another representation of the three-dimensional discrete data displayed in Figure 1 is the concentration profiles shown in Figure 3. Note that the copper concentration as detected in the center of the ceramic $\mathrm{MgO}$ precipitate is never less than 51 at.\% (see Fig. 3 and Table 1). This is in agreement with the results obtained using a 1D-APFIM (Shashkov and Seidman, 1995, 1996; Shashkov et al., 1999b), though it was never explicitly discussed.

Both Figures 2 and 3 show clearly the segregation of silver to the $\mathrm{MgO} / \mathrm{Cu}$ interface at a depth of approximately $5 \mathrm{~nm}$. Since the analysis cylinder was not exactly perpendicular to the posterior interface of the $\mathrm{MgO}$ precipitate, at a depth of approximately $20 \mathrm{~nm}$, the signal from the posterior interface was diffuse and segregation was not detected. Table 1 lists the measured values of the Gibbsian interfacial excess of $\mathrm{Ag}$ at the $\mathrm{MgO} / \mathrm{Cu}$ interface calculated utilizing our methodology (Shashkov and Seidman, 1995, 1996; Shashkov et al., 1999b) for the four different cylinder 


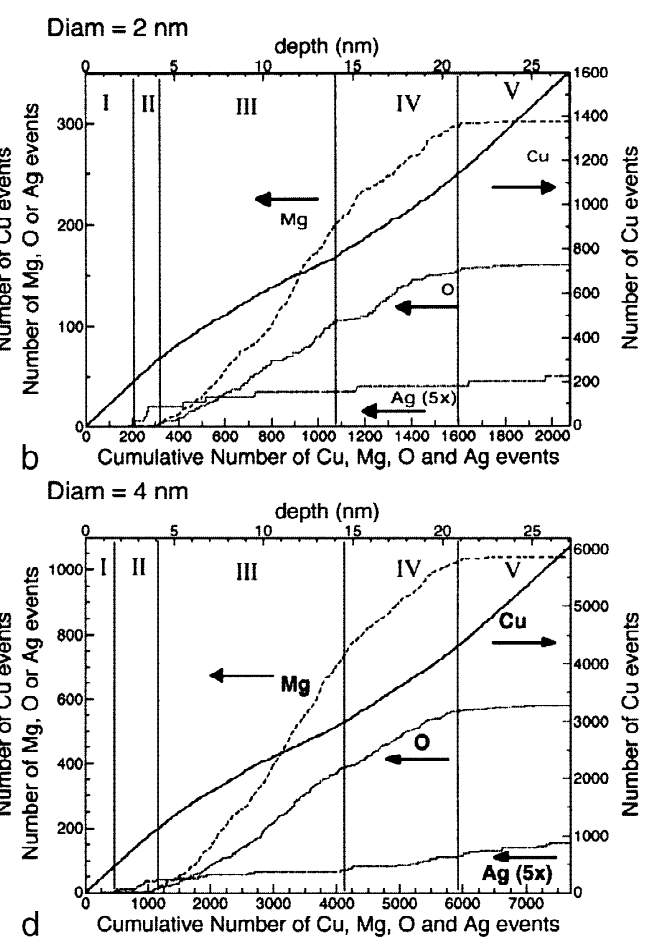

Figure 2. Integral profiles obtained from the analysis cylinder in Figure 1, with the value of the cylinder diameter employed shown in the upper left-hand corner of each profile (a-d). The profiles show the $\mathrm{Mg}$, $\mathrm{O}$, and Ag events (the latter is multiplied by five for the purpose of clarity) on the left-hand ordinate axes vs. the cumulative number of $\mathrm{Cu}, \mathrm{Mg}, \mathrm{O}$, and $\mathrm{Ag}$ events (the lower abscissa axes). The $\mathrm{Cu}$ events are indicated on the right-hand ordinate axes. diameters utilized. The values of the Gibbsian interfacial excess of silver shown in Table 1 range from $2.33 \times 10^{18}$ to $5.81 \times 10^{18} \mathrm{~m}^{-2}$ and they agree approximately with the average value, previously published, obtained employing a 1D-APFIM, $(4.0 \pm 1.9) \times 10^{18} \mathrm{~m}^{-2}$ (Shashkov et al., 1999b).

The high apparent copper concentration detected within the $\mathrm{MgO}$ precipitates is likely to be an artifact of the field evaporation process in the vicinity of a high-dielectric constant $\mathrm{MgO}$ precipitate. The presence of such a precipitate at the surface would alter the geometry of the local electric field, which is responsible for the divergence of ion trajectories, and for the natural magnification associated with field evaporation. A further alteration of the electric field would be caused by the difference in evaporation rates of the atoms in the particle and the matrix, resulting in either a protrusion or a depression at the surface of the $\mathrm{MgO}$ precipitate. This alteration would cause a decrease in the local resolution of the microscope, and hence cause some $\mathrm{Cu}$ atoms from the matrix to appear on the twodimensional detector at positions overlapping with those of events from the $\mathrm{MgO}$ precipitate.

We note that the ion optics are much more complicated than the analogous case with a protruding metal precipitate (Vurpillot et al., 1999a,b). If the dielectric constant of the matrix and precipitate are equal, then a protruding precipitate can be expected to produce a local magnification, and ions evaporated from the matrix would be ex- pected to have trajectories away from the precipitate, which could not place them inside the precipitate in the reconstruction. However, a non-metallic precipitate could cause the opposite effect, whereby a distortion of the electric field could cause a lensing effect pushing the trajectories of the matrix atoms toward the precipitate.

As a side note, the precipitates appear bright in a field ion microscope image, which is, for a metal specimen, a sign of a local protrusion. However, this could be explained not because of the local higher curvature at the precipitates, but instead by the higher electric field divergence caused by the intersection of the tip surface with the precipitate/ matrix phase boundary. Thus, while we suspect that the $\mathrm{MgO}$ precipitates do actually protrude from the surface during field evaporation, we cannot show conclusive evidence of this. A complete study of the many effects involved, including local geometry, the different dielectric constants of the particle and matrix, the different field evaporation rates of the materials, and the optics of the ion trajectories will require significant effort.

A second explanation would be that the $\mathrm{MgO}$ precipitate actually does contain a significant fraction of $\mathrm{Cu}$. This might conceivably arise from some unexpected kinetic pathway in the internal oxidation process. We think, however, this explanation is highly unlikely. This judgment is based on the fact that STEM and EELS measurements reveal (Muller et al., 1998; Shashkov et al., 1999b), and calcula- 


\section{Diameter $=2 \mathrm{~nm}$}

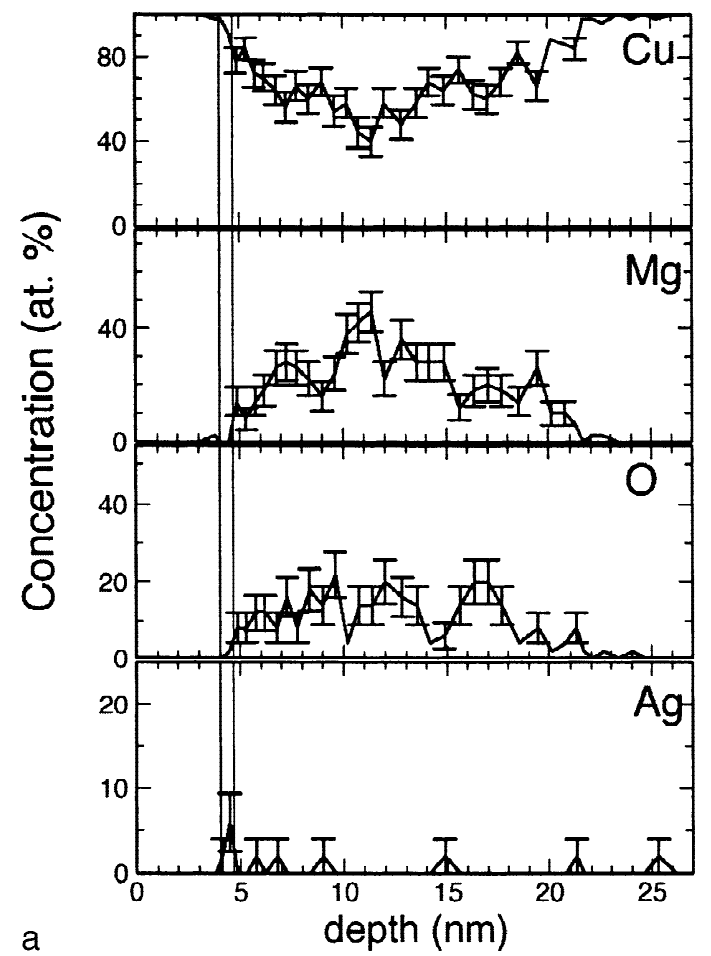

\section{Diameter $=3 \mathrm{~nm}$}

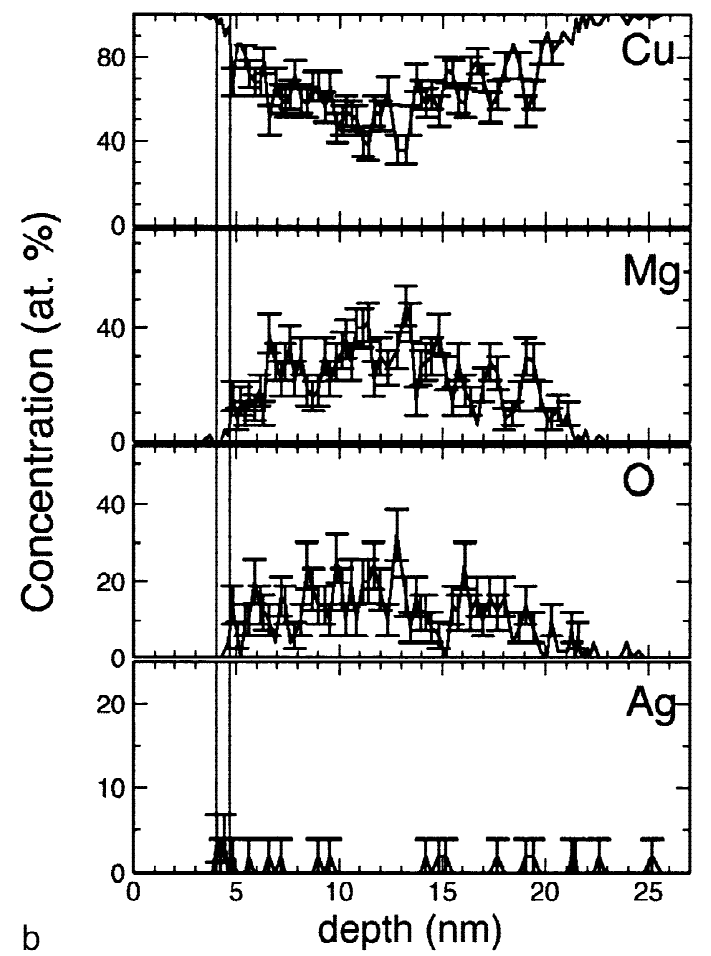

Figure 3. Concentration profiles $(\mathbf{a}, \mathbf{b})$ of the analysis cylinders in Figure $2 \mathrm{~b}$ and $\mathrm{c}$ for two different analysis diameters. A block size of 50 atoms per block was used to calculate the silver concentrations. The error bars in this figure correspond to a single standard deviation. tions predict (Benedek et al., 1996, 1997, 1999, 2000), a nearly complete separation of $\mathrm{MgO}$ from $\mathrm{Cu}$. Furthermore, unpublished 1D-APFIM measurements of similar samples have found pure $\mathrm{MgO}$ particles: that is, no $\mathrm{Cu}$ atoms were detected in $\mathrm{MgO}$ precipitates (Rüsing, unpublished data). We note that in previous 1D-APFIM studies, the detection of $\mathrm{Cu}$ atoms along with $\mathrm{Mg}$ and $\mathrm{O}$ atoms could have been explained by the placement of the aperture in the channel multiplier array such that atoms were collected from both matrix and precipitate (Shashkov, 1997). The present study indicates that this explanation is not sufficient.

The most important information gained from this study comes from the chemical characterization of the $\mathrm{MgO} / \mathrm{Cu}$ interfaces. Figures 2 and 3 demonstrate clearly that the concentration of $\mathrm{Ag}$ is enhanced locally at the $\mathrm{C} / \mathrm{M}$ interface relative to the matrix. Table 1 demonstrates that if a single standard deviation is applied to the measured levels of silver segregation (relative to the nominal silver content of the matrix) then the ratio of one sigma to the Gibbsian interfacial excess varies from $0.712(\mathrm{~d}=1 \mathrm{~nm})$ to $0.316(\mathrm{~d}$ $=3 \mathrm{~nm}$ ). To improve the statistical uncertainty, a new statistical method called a proximity histogram (or proxigram for short) was developed (Hellman et al., 2000). This method allows for the calculation of the silver concentration in three dimensions around an individual $\mathrm{MgO}$ precipitate. A precipitate is defined by employing an isoconcentration surface, and the level of segregation is calculated as a function of the minimum distance to this surface.

Figure 4 shows the results of a proxigram analysis for the species silver. Positive values on the $\mathrm{x}$-axis (abscissa) correspond to the $\mathrm{Ag}$ concentration in the $\mathrm{MgO}$ precipitate, defined by the isoconcentration surface at 11 at.\% $\mathrm{mg}$. This value defines the $\mathrm{C} / \mathrm{M}$ interface to be near to the point of the steepest magnesium concentration gradient. The total Ag concentration for the $3 \mathrm{D}$ reconstruction is 0.5 at. $\%$ and it is drawn as a horizontal line in Figure 4. Note that the Ag concentration decreases with distance from the interface, toward the direction of the center of the precipitate. No silver is detected inside the precipitate, which is consistent with its very limited solid-solubility in $\mathrm{MgO}$. Outside the precipitate, an unambiguous silver enhancement is observed with respect to the 0.5 at. $\%$ Ag matrix concentration. In the first $5 \mathrm{~nm}$, the Ag concentration is increasing to approximately 0.614 at. $\%$ and the single standard deviation is clearly above the average concentration. The two data points of the proxigram that show enhancement near the interface each represent layers of approximately 25,000 particles, and thus the measured excess in the two layers cor- 
Table 1. Results of the Nanochemical Analysis of an MgO Precipitate in a Copper (Silver) Matrix, with Ag Atoms Segregated at This Ceramic/Metal Interface ${ }^{\mathrm{a}}$

\begin{tabular}{lllr}
\hline $\begin{array}{l}\text { Diameter }(\mathrm{d}) \\
\text { of cylinder }(\mathrm{nm})\end{array}$ & $\begin{array}{l}\text { Apparent copper concentration } \\
\text { in } \mathrm{MgO} \text { precipitate }(\text { at.\%) }\end{array}$ & $\begin{array}{l}\text { Segregation concentration } \\
\text { of } \mathrm{Ag} \text { at } \mathrm{MgO} / \mathrm{Cu} \text { interface }(\text { at.\%) }\end{array}$ \\
\hline 1 & $51.8 \pm 7.1$ & $8.3 \pm 8$ & $(5.69 \pm 4.05) \cdot 10^{18}$ \\
2 & $60.1 \pm 3.5$ & $4.2 \pm 4.1$ & $(5.81 \pm 2.11) \cdot 10^{18}$ \\
3 & $59.9 \pm 2.5$ & $2.8 \pm 2.3$ & $(3.96 \pm 1.23) \cdot 10^{18}$ \\
4 & $62.9 \pm 1.7$ & $1.8 \pm 1.5$ & $(2.33 \pm 0.88) \cdot 10^{18}$
\end{tabular}

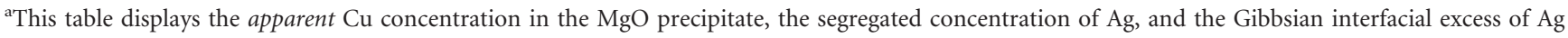
at the interfacial region, including the single standard deviation uncertainty.

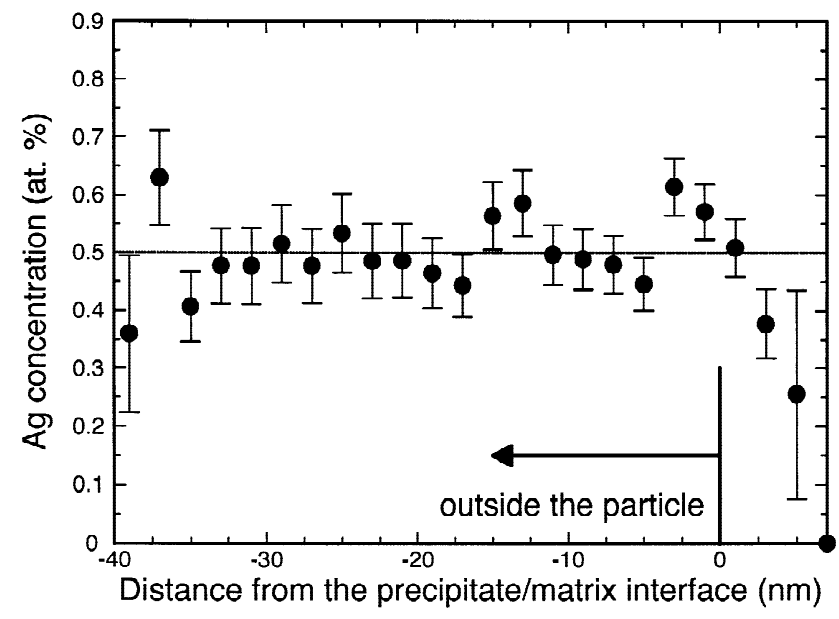

Figure 4. Silver concentration as a function of the distance to the $\mathrm{Cu} / \mathrm{MgO}$ interface for two $\mathrm{MgO}$ precipitates. The interface was defined by an isoconcentration surface at 11 at.\% $\mathrm{Mg}$. This figure is called a proximity histogram or proxigram for short (Hellman et al., 2000).

responds to approximately $46 \mathrm{Ag}$ atoms, above the $250 \mathrm{Ag}$ atoms expected in the layers for a bulk composition of 0.5 at.\%. Further away in the matrix (distance greater than 17 $\mathrm{nm}$ ), the Ag concentration again reaches the average matrix concentration.

A second increase of the Ag segregation at a distance of about $12 \mathrm{~nm}$ from the precipitate is indicated. This second enhancement is not expected. It is possible that this arises due to the presence of one or more precipitates that are not seen in the analysis volume. Additionally, it is noted that an experimental error (e.g., applying the analysis cylinder at an angle other than $90^{\circ}$ to the interface) is impossible when applying proximity histogram analysis.

Ag segregation to this interface is likely due to a local stress effect, which could be embodied in two ways: first, if there are defects such as dislocations present in the $\mathrm{Cu}$ near the $\mathrm{MgO}$ precipitates, Ag is expected to exhibit segregation to such dislocations. Second, Ag segregation would cause an elastic softening of the matrix, reducing the local strain energy associated with the presence of precipitates.

\section{Conclusions}

In this article, a nanochemical investigation of an $\mathrm{MgO} / \mathrm{Cu}$ interface in three dimensions is presented. It is clearly shown by a $3 \mathrm{D}$ reconstruction of an atom probe analysis that silver in the system $\mathrm{MgO} / \mathrm{Cu}(\mathrm{Ag})$ segregates at this $\mathrm{C} / \mathrm{M}$ interface. The Gibbsian interfacial excess of silver is calculated employing our procedure (Krakauer and Seidman, 1993) and the values obtained are in agreement with our previous measurement of this quantity (Shashkov and Seidman, 1995, 1996; Shashkov et al., 1999b). Additionally, the application of a new statistical method, the proximity histogram (or proxigram for short), to analyze $3 \mathrm{D}$ atom-probe data with respect to characterization of segregation at an interface is presented (Hellman et al., 2000). It is demonstrated that a proxigram excludes errors due to an imprecisely defined crystallographic direction of a cylinder with respect to an interface and it also decreases the standard error in the measured level of segregation.

\section{ACKNOWLEDGMENTS}

J. Rüsing, J.T. Sebastian, and D.N. Seidman were supported at Northwestern University by the U.S. Department of En- 
ergy, Office of Basic Energy Sciences, under grant DEFG02ER45597. O.C. Hellman was supported by the National Science Foundation, Division of Materials Research.

\section{REFERENCES}

Barreau G, Brunel G, Cizeron G, Lacombe P (1970) Détermination des coefficients d'hétérodiffusion en volume et aux joints de grains de l'argent dans le cuivre pur et influence des éléments d'addition: chrome, tellure, titane et zirconium, sur ces coefficients. C R Acad Sci C270:516-519

Benedek R, Minkoff M, Yang LH (1996) Adhesive energy and charge transfer for $\mathrm{MgO} / \mathrm{Cu}$ heterophase interfaces. Phys Rev B54: 7697-7700

Benedek R, Seidman DN, Yang LH (1997) Atomistic simulation of ceramic/metal interfaces: $\{222\} \mathrm{MgO} / \mathrm{Cu}$. Microsc Microanal 3: $333-338$

Benedek R, Seidman DN, Minkoff M, Yang LH, Alavi A (1999) Atomic and electronic structure, and interatomic potentials at a polar ceramic/metal interface: $\{222\} \mathrm{MgO} / \mathrm{Cu}$. Phys Rev B60: 16094-16104

Benedek R, Alavi A, Seidman DN, Yang LH, Muller DA, Woodward C (2000) First principles simulation of a ceramic/metal interface with misfit. Phys Rev Lett 84:3362-3365

Blavette D, Deconihout B, Bostel A, Sarrau JM, Bouet M, Menand A (1993) The tomographic atom probe: a quantitative threedimensional nano-analytical instrument on an atomic scale. Rev Sci Instrum 64:2911-2919

Cerezo A, Godfrey TJ, Sijbrandi SJ, Smith GDW, Warren PJ (1998) Performance of an energy-compensated three-dimensional atom-probe. Rev Sci Instrum 69:49-58

Deconihout B, Pareige C, Pareige C, Blavette D, Menand A (1999) Tomographic atom probe: new dimension in materials analysis. Microsc Microanal 5:39-47

De Hosson JTM, Vellinga WP, Zhou XB, Vitek V (1996) Structure-property relationship of metal-ceramic interfaces. In: Stability of Materials, Gonis A, Turchi PEA, Kudmovsky J (eds). New York: Plenum, pp 581-614

Ernst F (1995) Metal-oxide interfaces. Mater Sci Eng R14:97-156

Felten EJ, Pettit FS (1976) Development, growth, and adhesion of $\mathrm{Al}_{2} \mathrm{O}_{3}$ on platinum-aluminum alloys. Oxid Met 10:189-223.
Hellman OC, Vandenbroucke JA, Rüsing J, Isheim D, Seidman DN (2000) Analysis of three-dimensional atom-probe data by the proximity histogram. Microsc Microanal 6:437-444

Jang H, Seidman DN, Merkle KL (1993) The chemical composition of a metal/ceramic interface on an atomic scale: the $\mathrm{Cu} / \mathrm{MgO}$ $\{111\}$ interface. Interface Sci 1:61-75

Krakauer BW, Seidman DN (1993) Absolute atomic scale measurements of the Gibbsian interfacial excess of solute at internal interfaces. Phys Rev B48:6724-6727

Mader W, Rühle M (eds) (1992) Proceedings of the International Symposium on Metal-Ceramic Interfaces. Acta Metall 40S

Muller DA, Shashkov DA, Benedek R, Yang LH, Silcox J, Seidman DN (1998) Atomic scale observations of metal-induced gap states at $\{222\} \mathrm{MgO} / \mathrm{Cu}$ interfaces. Phys Rev Lett 80:4721-4744

Rozdilsky I (1999) 3-D Atomic-scale Characterization of Growing Precipitates. DPhil Thesis, University of Oxford

Rühle M, Evans AG, Ashby MF, Hirth JP (eds) (1990) Metalceramic interfaces: Proceedings of the International Workshop. New York: Pergamon

Shashkov DA (1997) Atomic-scale Studies of the Structure and Chemistry of Ceramic/metal Heterophase Interfaces. $\mathrm{PhD}$ Thesis, Northwestern University

Shashkov DA, Seidman DN (1995) Atomic scale studies of segregation at ceramic/metal heterophase interfaces. Phys Rev Lett 75: $268-271$

Shashkov DA, Seidman DN (1996) Atomic scale studies of silver segregation at $\mathrm{MgO} / \mathrm{Cu}$ heterophase interfaces. Appl Surf Sci 94/ 95:416-421

Shashkov DA, Chisholm MF, Seidman DN (1999a) Atomic-scale structure and chemistry of ceramic/metal interfaces-I. Atomic structure of $\{222\} \mathrm{MgO} / \mathrm{Cu}$ interfaces. Acta Mater 47:3939-3951

Shashkov DA, Muller DA, Seidman DN (1999b) Atomic-scale structure and chemistry of ceramic/metal interfaces-II. Solute segregation at $\mathrm{MgO} / \mathrm{Cu}(\mathrm{Ag})$ and $\mathrm{CdO} / \mathrm{Ag}(\mathrm{Au})$. Acta Mater 47: 3953-3963

Vurpillot F, Bostel A, Blavette D (1999a) The shape of field emitters and the ion trajectories in three-dimensional atom probes. $J$ Microsc 196:332-336

Vurpillot F, Bostel A, Menand A, Blavette D (1999b) Trajectories of field emitted ions in 3D atom probe. Eur Phys J AP 6:217-221 